\title{
The prevalence of obesity in mature Icelandic horses in Denmark
}

\author{
Rasmus Bovbjerg Jensen*, Signe Hartvig Danielsen, Anne-Helene Tauson \\ From Animal Obesity - causes, consequences and comparative aspects \\ Uppsala, Sweden. 14-16 June 2015
}

\section{Introduction}

Obesity is related to the development of several diseases like insulin resistance and laminitis in horses. The prevalence of obesity among mature Icelandic horses in Denmark has not been investigated previously.

\section{Objectives}

This study aimed to find the prevalence of obesity among mature Icelandic horses in Denmark, to compare body condition score (BCS) based on owner perception with that of an experienced person and to correlate the $\mathrm{BCS}$ to body weight (BW) and morphometric measures.

\section{Material and methods}

A total of 252 Icelandic horses ( $\geq 4$ years; 142 geldings, 101 mares, 9 stallions) from 46 different barns were included. All horses were assigned a BCS on a scale from 1-9 (1 is poor, 5 is moderate and 9 is extremely fat) by their owner and by an experienced person. A horse with a BCS of $\geq 7$ is considered to be obese. Two weight tapes (WT) were used to asses BW. Neck circumference and height at withers were measured, and the ratio between them calculated (NCHR).

\section{Results}

The BCS assigned by the owners correlated with the experienced person $(\mathrm{p}=0.001, \mathrm{r}=0.57)$, and horses with a BCS of 3-4, 5-6 and 7-9 were 5.9, 70.1 and $24.0 \%$, respectively. The $\mathrm{BCS}$ correlated to $\mathrm{BW}$ estimated with a WT $(\mathrm{p}=0.001, \mathrm{r}=0.70)$ and NCHR $(\mathrm{p}=0.001$, 0.34 ), although the latter correlation was poor. The BW was systematically $19 \pm 15 \mathrm{~kg}$ higher with WT 1 than 2.

\footnotetext{
* Correspondence: ralle@sund.ku.dk

Department of Veterinary Clinical and Animal Sciences, University of
} Copenhagen, Copenhagen, Denmark

(c) 2015 Jensen et al. This is an Open Access article distributed under the terms of the Creative Commons Attribution License (http:// creativecommons.org/licenses/by/4.0), which permits unrestricted use, distribution, and reproduction in any medium, provided the original work is properly cited. The Creative Commons Public Domain Dedication waiver (http://creativecommons.org/publicdomain/ zero/1.0/) applies to the data made available in this article, unless otherwise stated. 